attention. This would be a mistake, for the results ${ }^{1}$ emphasize points of practical importance applicable to India but also to a wider world.

The hospital records were studied of 200 women on whom tubal ligation had been performed up to nine years previously. An experienced social worker interviewed 146 after a houseto-house search of the villages concerned. Operation had been performed in the puerperium in 133, at Caesarean section in 8 , and intrapartum in 5 . The women and their husbands were better educated than the general population of the area. Moreover, both were more literate (husbands particularly so) than those couples who relied on the intrauterine device. In spite of this $68 \%$ had either never heard of birth control or had never used it prior to operation.

An important finding was that before operation 89 of the women consulted 163 friends who had previously had tubal ligation. All advised in its favour, and of the 146 interviewed $98 \%$ advised others to have the same operation. Average age at operation was 30 , though tubal ligation was performed on 15 women in the 20-24-year range and on 3 aged 40-44. The average duration of marriage prior to operation was 13 years and the average number of children was 5, though many women stated they would have requested operation earlier had they known about it. Most preferred to have a son before sterilization.

Similar results have been reported from Puerto Rico, ${ }^{2}$ where $94 \%$ of 519 women expressed satisfaction after operation, and from Pakistan. ${ }^{3}$ In Japan ${ }^{4}$ the number of sterilizations increased from fewer than 6,000 in 1959 to over 44,000 by 1966 , and in Britain $4 \%$ of women admitted to gynaecological wards in 1966 had tubal ligations. ${ }^{5}$

When dealing with the millions of India or Pakistan the logistics of sterilization are formidable. Its contribution will depend on its acceptability and the facilities available for its performance. Male sterilization is quicker, less traumatic, and does not require admission to hospital, but unless suspicions are dispelled and acceptability improved its potential will not be realized. Laparoscopic sterilization as advocated by P. C. Steptoe $^{6}$ would be the nearest comparable technique in women, but it requires delicate and expensive equipment, considerable skill, and admission to hospital. Puerperal sterilization, which was the method most widely used in the series reviewed, has most to offer. The patient can be discharged within a week of delivery and operation.

Restoration of fertility can never be promised, and for this reason tubal ligation should be regarded as permanent and should not be performed if either partner is undecided about further pregnancy. Selection of patients is therefore most important. The implications of the operation should be explained to both husband and wife, and their written consent is essential. Finally, as reported from Oxford, ${ }^{78}$ tubal ligation is contraindicated in a sizeable group of women with uterine disease, for whom hysterectomy is a better procedure. With

1 Lippitt, T., Ranganathan, K. V., and Hulka, J. F., American fournal of Obstetrics and Gynecology, 1969, 105, 434.

2 Paniagua, M. E., Tayback, M., Janer, J. L., and Vázquez, J. L., American fournal of Obstetrics and Gynecology, 1964, 90, 421 .

3 Roberts, Beryl, J., et al., fournal of the Pakistan Academy of Rural Develop-

4 Koya, Y., Eugenics Quarterly, 1961, 8, 135.

- Peel, J., Fournal of Obstetrics and Gyinaecology of the British Commonwealth, 1969, 76, 1042.

6 Steptoe, P. C., Fournal of Obstetrics and Gynaecology of the British Commonwealth, 1969, 76, 1043.

7 Stallworthy, J. A., fournal of Obstetrics and Gynaecology of the British Commonwealth, 1969, 76, 1042.

8 Williams, E. A., Lancet, 1969, 1, 1093. these reservations, tubal ligation is an effective method of family planning which deserves wider recognition, both in Britain and abroad.

\section{Surgical Contrasts}

One of the enigmas facing the planners in this spring of Green Papers must be the relationship between the demand for medical services and the need for them. Many people seem to clamour for more than can be good for them; a modest minority are thought to receive too little for their health. But that striking a balance between demand and need is not a problem peculiar to the welfare State is evident from a recent article in the U.S.A. Dr. John P. Bunker ${ }^{1}$ reports that there are twice as many surgeons in proportion to population in the U.S.A. as in England and Wales and that, likewise in proportion to population, they perform twice as many operations as their confrères over here. No wonder the New England fournal of Medicine asks, "What puts the surge in surgery?"

The question that naturally comes to mind is whether Americans are getting too much and Britons too little surgery -though the alternatives of whether both are getting too much or too little cannot be altogether excluded. Part of the discrepancy between the two countries can be attributed to a real need for more surgery in the U.S.A. in the treatment of road accidents-a need that is fulfilled-and to the difference must be added a need that goes unfulfilled over here, according to Dr. Bunker. He says "many British physicians believe that there are a large number of patients in need of surgery for cataract, and the long waiting lists for herniorrhaphy and prostatectomy are common gossip." But of course against the hazard of having one of these conditions untreated must be weighed the hazard of the operation itself. The difficulty of balancing these chances with any precision for the individual patient points also to another dilemma: what is this "need" to match against "demand"?

At first sight it might be thought that operations which are free at the time under our Health Service would be relatively more numerous than the often expensive procedures under American private enterprise, with or without insurance cover. But in the organization of medical care over here the place of the general practitioner is in many ways crucial. Certainly those who in moments of despondency think of themselves as little more than a filter are vastly underrating their role. It is the British family doctor's much greater familiarity with his patients than is possible to many American doctors that enables him to assess their real needs more accurately. Patients who can go straight to surgeons, as they do in the U.S.A., will probably get a surgical answer to their worries. As Dr. Bunker puts it, surgeons and nonsurgeons are apt to have very different ideas of indications for surgery. But as well as divergence in the medical organization of the two countries Dr. Bunker sees differences in surgical philosophy. "In keeping with his national character the American surgeon is more aggressive." The British surgeon "is more modest in his expectations, possibly more realistic, but also possibly missing opportunities for surgical cure." It is especially in elective procedures that these different outlooks may show their effects most plainly.

\footnotetext{
${ }^{1}$ Bunker, J. P., New England fournal of Medicine, 1970, 282, 135.
} 
Another great advantage of the British system by which general practitioners have separate functions from consultants is that the consultants really are that and not simply specialists. In the U.S.A., according to Dr. Bunker, while individual hospitals may require board certification or equivalent training, many do not. Fewer than two-thirds of the 68,000 physicians listed in full-time or part-time private practice of surgery are certified by a surgical board or are fellows of the American College of Surgeons. The consequence in surgery, as he handsomely concedes, is that on the average "its quality in England and Wales must be considered superior to that in the United States."

\section{Surgery for Cervical Spondylosis}

Cervical spondylosis is common and may be very disabling, for it can cause pain, weakness of the arms, and degrees of damage to the cord up to paraplegia, bladder paralysis, and sensory extinction. The radiculopathies and myelopathy, which are the chief features of the syndrome, are complications of the osteophytic outgrowths found in the vertebral canal or in relation to the apophysial joints. These are a result of degeneration of intervertebral discs and have been found in $75 \%$ of a sample of hospital patients admitted for other conditions."

Much attention has been paid to the possibility that the myelopathy and radiculopathy are caused by direct compression. This has in turn been attributed not only to the osteophytes, but also to posterior indentation of the dura by the ligamenta flava and to fixation of the dura to the intervertebral foramina and ligamenta flava. The tethering action of the dentate ligaments between the dura mater and the cord has been thought to distort the cord; and congenital narrowness of the vertebral canal, with or without vertebral instability, may make the cord more vulnerable to compression. W. G. P. Mair and R. Druckman ${ }^{2}$ showed that the myelopathy might be associated with softening and cavitation of the cord, and that this is distributed in a manner suggesting an ischaemic origin, which they attributed to compression of the anterior spinal artery.

B. G. Chakravorty ${ }^{3}$ has studied the blood supply of the cervical cord in man by injection techniques in cadaver specimens. He finds that the contribution of the vertebral artery to the anterior spinal artery does not extend below the third cervical level and that there is only a sparse anastomosis between the anterior and posterior spinal arteries. He confirms that radicular arteries maintain the blood supply below this level by contributing to the longitudinal anastomosis. They do this in varying degree. Radicular arteries of significant size are few in number and seldom exceed three. In two-thirds of his sample of 31 necropsy specimens only one was present. These larger vessels accompanied the fourth to sixth cervical roots, which are commonly affected by cervical spondylosis. He believes that compression of essential radicular arteries is a more likely cause of myelopathy than compression of the anterior spinal artery and that the dural root sleeve should be decompressed in order to restore the circulation.

The radiological investigation of a case of cervical spondylosis must include the standard projections for the neck, including oblique views and lateral views taken in flexion and extension. These help to show the extent of the disease and also instability. Before an operation is carried out myelography should be performed to detect compression of the dural envelope, cervical roots, and spinal cord. To obtain adequate information this examination should be done in both prone and supine positions, and it calls for expert radiology. Discography has its advocates but is not widely used. The most degenerate discs may not be causing the greatest harm. By these means, and careful clinical examination, angiomas of the cord and tumours will not be mistaken for disc lesions, and the type of operation most suited to the patient can be decided upon.

Conservative measures should usually be tried first, but when surgery is considered a number of techniques are now available. Each is aimed at a different aspect of cervical disease. Anterior interbody fusion by the Robinson-Smith or Cloward method provides stability when this is at fault. The operation entails excision of a cervical disc by an anterior approach, with the insertion of a bone graft between the two vertebral bodies, and it allows osteophytes to be removed more safely than by a posterior approach. Microsurgical methods and a high-speed drill may be an additional help. Though the intervertebral foramen may be widened when an interbody graft is inserted, it cannot be decompressed by the anterior approach.

When compression of the cord is shown to be extensive and due to multiple disc abnormalities, a congenitally narrow canal, or folded ligamenta flava, then laminectomy is indicated. Some surgeons consider it better not to open the dura, but emphasize the importance of freeing adhesions around roots within the foramina, for which foraminotomy is necessary. Others consider the dura should be divided widely and held open. Division of dentate ligaments is done less commonly than formerly and has been blamed for aggravation of cord lesions. It is not easy to determine the main radicular arteries during life except by inspection, but if the dura is opened some idea may be obtained. If Chakravorty is correct, foraminotomy at the appropriate level may prevent myelopathy or arrest its progress, but it is not likely to reverse changes already brought about by ischaemia. Little progress has been made so far in the prevention of cervical spondylosis and its sequelae.

Pallis, C., Jones, A. M, and Spillane, J. D., Brain, 1954, 77, 274.

2 Pruckman, R., Brain, 1953, 76, 70

2 Mair, W. G. P., and Druckman, R., Brain, College of Surgeons of England, 1969, 45, 232 .

4 Stoops, W. L., and King, R. B., Fournal of the American Medical Association, 1965, 192, 281 . 